\title{
Evaluation of Paralleled Generation Architectures for Civil Aircraft Applications
}

\author{
Theodoros Kostakis, Patrick Norman, Steven Fletcher, Stuart Galloway and Graeme Burt
}

University of Strathclyde

\begin{abstract}
The aviation industry has witnessed a technological shift towards the More Electric Aircraft (MEA) concept. This shift has been driven by a number of perceived benefits including performance optimization and reduced life-cycle costs. Increased electrification within MEA has made aircraft electrical networks larger and more complex and this necessitates an increased electrical power offtake from the engine. The paralleling of multiple generation sources across the aircraft is one potential design approach which could help improve engine operability and fuel efficiency within more-electric aircraft platforms. Accordingly, this paper will investigate options for the realization of paralleled generation systems within the context of current design and certification rules. The paper first illustrates, through simulation, that MIL-STD-704F voltage envelopes may be breached for some interconnected electrical architectures under fault conditions. The paper then assesses various solution options to minimize the propagation of transients across the interconnected network and demonstrates their effectiveness with reference to appropriate power quality standards. The paper concludes by providing estimates of the impact of each of these solution options on the total weight of the electrical system, highlighting how different designs and operating strategies can influence the design at a systems level.
\end{abstract}

\section{Introduction}

In addition to providing thrust, the engines on a conventional civil aircraft generate power for non-propulsive on-board systems in the form of pneumatic, electrical and mechanical power. For example, cabin air-conditioning and pressurization traditionally use pneumatic power, engine fuel and oil pumps require mechanical power and electrical power is utilized mainly for cabin loads, lights and avionics $[1,2]$.

However, in recent generations of airliners, like the Boeing 787 and the Airbus A380, many or all of the above mentioned loads are electrically powered. Airframers claim that these 'more-electric' technologies have brought along benefits such as weight reductions, optimized performance and reductions in the life-cycle cost for the aircraft operator [3]. However it has also increased the on-board electrical generation and distribution requirements, which consequently increase the size and complexity of the electrical network. With rising aviation-fuel costs and strict environmental constraints, there is an ever-growing need for new, lightweight and efficient power systems. New architectures that facilitate optimized power extraction from the aircraft engine need to be considered. To this end, on-engine or on-airframe interconnected generation

Page 1 of 8 (supporting multi-shaft offtakes and power sharing for example) may offer engine operability and fuel efficiency benefits, as well as potentially increase the reliability of supply to flight-essential loads $[4,5]$.

This paper will provide a brief historical review of interconnected generation in the aviation sector and address the certification challenges related to paralleled architectures. The paper then presents software models of a dual/multiple generator networks to provide an in-depth analysis into the behavior of a DC-interconnected electrical system. Simulation studies will investigate the impact of the desired type of compliance and the speed of protection operation on the weight of the airplane electrical system. The paper concludes by identifying the design trade-offs for the realization of compliant interconnected power networks.

\section{Interconnected Generation}

\section{Historical Review}

In the current aviation industry, interconnected generation is relatively rare. Most aircraft platforms operate isolated radial architectures, featuring redundant cabling. The rationale behind this approach is that essential systems are adequately provided with electrical power, despite faults or transients occurring at any point in the network [6].

However, the first production passenger jet aircraft, the four-engine De Havilland Comet, which entered active service in 1952, featured a full-DC electrical system. It utilized a $2.5 \mathrm{kVA}$ generator per engine and all generators were connected to a common DC busbar via individual rectifiers [7]. In case of a fault, the common busbar could be split for safety reasons.

Boeing also used interconnected generation on its four-engine 707, 720,727 and 747 passenger aircraft, featuring a three-phase $115 \mathrm{~V}$ $400 \mathrm{~Hz}$ AC electrical system [8-10]. When Boeing however rolledout the two-engine 737, and all subsequent two-engine aircraft, the previous interconnected architecture was replaced by an isolated twochannel architecture [11].

Figure 1 depicts the interconnected electrical system of the B747, which features interconnected generation on both the $115 \mathrm{~V}$ AC and 28 V DC levels. Each generator is connected via a Generator Circuit Breaker (GCB) to its respective bus, which closes when 'satisfactory' power quality is achieved. The generators are interconnected when all Bus Tie Breakers (BTBs) are closed and each AC bus is synchronized. The Sync bus can be split in two channels via the Split 
System Breaker (SSB). Each DC bus is powered from its respective AC bus through a Transformer Rectifier Unit (TRU) and is connected to the DC tie bus via DC Isolation Relays (DCIRs). When all DCIRs are closed, the DC buses are paralleled [12].

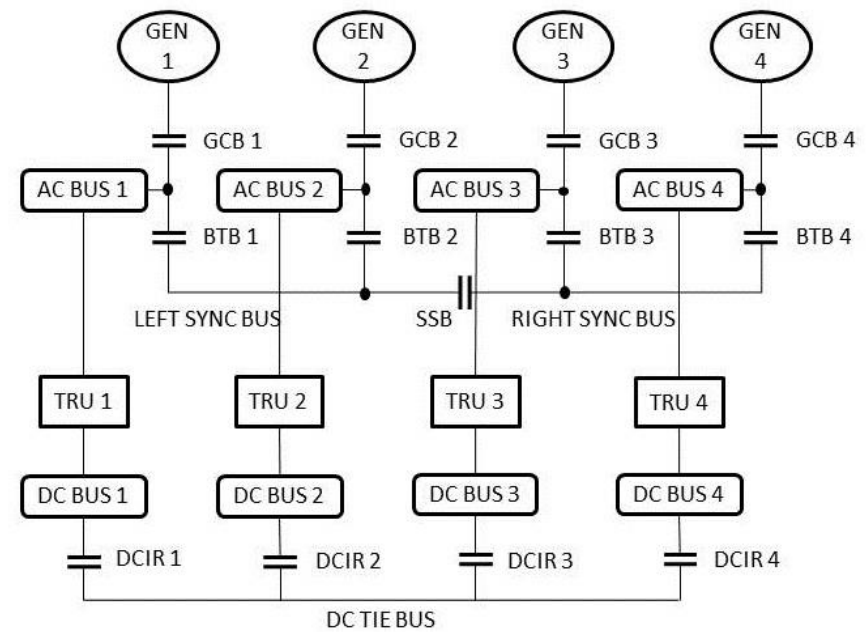

Figure 1. Depiction of the interconnected B747 electrical system (adapted from [13]).

Although all interconnecting circuit breakers remain closed during normal flight conditions, the buses are automatically isolated below $1,500 \mathrm{ft}$ until landing to provide independent power supplies to the three auto-pilots of the auto-land system [12].

\section{Implementation Challenges}

\section{Power Generation System}

For the past few decades, the predominant civil aircraft generation system has been the Integrated Drive Generator (IDG). Chang and Wang [14] estimate that $95 \%$ of in-service passenger aircraft were at one point equipped with IDGs. An IDG comprises of a variable-input mechanical gearbox and a constant-output shaft connected to the generator. Regardless of the rotational speed of the engine, the IDG produces a three-phase, $400 \mathrm{~Hz}$ constant-frequency AC output voltage. Due to this constant-frequency characteristic, AC interconnections, as on the B747, could be readily implemented.

In the recent years though, there has been a shift in the aviation industry towards the more efficient Variable Frequency Generator (VFG). Compared to the IDG, the VFG does not require a heavy gearbox, it can self-start the engine and is considered to be the most reliable generator technology [15]. It too produces three-phase AC power however the output frequency varies from $320 \mathrm{~Hz}$ to $800 \mathrm{~Hz}$ depending on the engine spool speed. Both the B787 and the A380 are equipped with VFGs, consequently AC interconnections on these MEA seem unfeasible without additional frequency-regulating equipment.

A more feasible route for paralleled generation may be provided by using higher voltage DC distribution, the use (or at least interest) of which is growing within MEA [3] and More Electric Engine [16] systems. There are a number of reasons for the growth of DC systems. The paralleling of non-synchronous power sources is better facilitated using DC distribution, as utilizing DC eliminates the need for frequency and phase synchronization [17]. DC distribution also facilitates a reduction in cable size and weight [17]. Compared to an AC architecture, research has shown that a DC architecture may provide a more efficient electrical network [15, 19], partly by reducing the number of power conversion stages between source and load [17] and also by allowing the generators to operate at more efficient operating points [20]. Given the potential benefits offered by DC distribution for interconnected systems, an interconnect DC electrical architecture will be the primary platform studied within this paper.

\section{Airworthiness Standards}

In the US, the Federal Aviation Administration has set the airworthiness requirements for aircraft and systems design which are maintained in Title 14 of the Code of Federal Regulations [21]. Similarly in Europe, the European Aviation Safety Agency maintains its "Certification Specifications for Large Aeroplanes CS-25" [22]. Due to the similarity of the two codes, only CS-25 will be discussed in this paper.

CS-25 requires that the power system as a whole, including all power sources, distribution equipment and converters, continues to supply essential loads "after any failure or malfunction in any one power supply system, distribution system, or other utilization system". It is further stipulated that in order to satisfy the above requirement, any duplicate systems must be sufficiently isolated "to minimize the risk of a single occurrence causing multiple failures of circuits or power supplies of the system concerned". Additionally, power sources are required to "function properly when independent and when connected in combination", however "no failure or malfunction of any power source can create a hazard or impair the ability of remaining sources to supply essential loads". This suggests that, to a degree, interconnections are compatible with the standards, but significant design undertaking and satisfactory protection performance are required to achieve acceptable levels of reliability on an interconnected system.

\section{Power Quality Requirements}

The on-board electrical system is required to provide electrical power of 'satisfactory quality' at the terminals of all utilization equipment, during all operations of the system. Power-quality requirements, such as voltage magnitude, phase, transients and frequency for AC or DC systems, are defined in power quality standards such as the US Military Standard 704F (MIL-STD-704F) [23]. Figure 2 illustrates the restrictions on the DC voltage profile during a transient under normal operation. One possible interpretation of the these standards is that in any paralleled system, a fault on any one supply channel should not cause the voltage of the remaining channels to deviate out of the acceptable transient limits defined in MIL-STD-704F. This interpretation will be used as the basis for simulation studies in the following sections. 


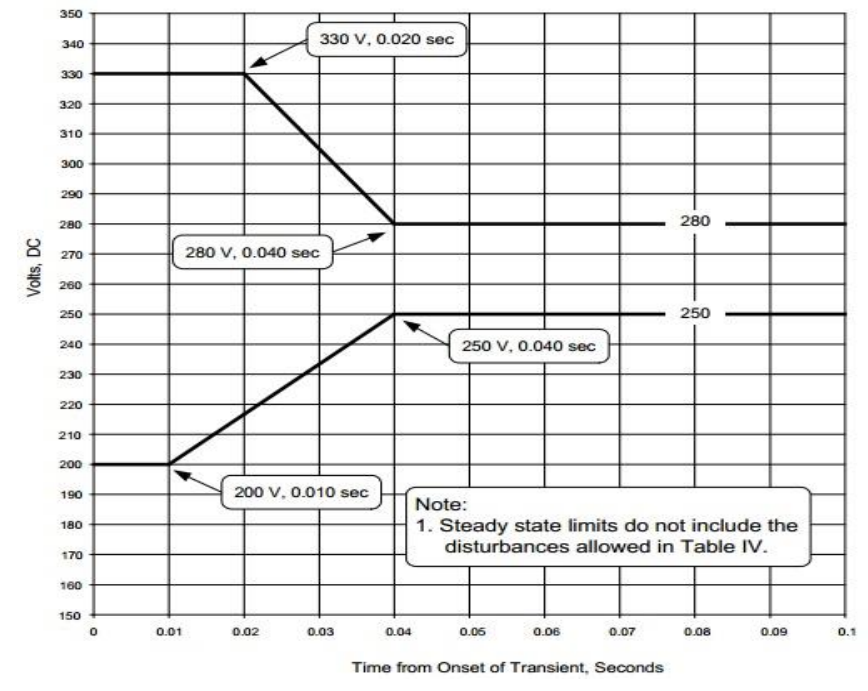

Figure 2. Normal voltage transient envelope for $270 \mathrm{~V}$ DC systems [23].

\section{Simulation Analysis}

\section{Network model}

To investigate the efficacy of possible solutions for the feasible realization of regulations-compliant DC interconnected networks, a two-generator, $270 \mathrm{~V}$ DC paralleled distribution network model has been developed using the Simulink software package. An outline of this network is shown in Figure 3. Three- and four-generator models at the same total rated power (indicative of more-electric engine and fully interconnected aircraft systems) are also presented later in the paper.

Voltage-behind-impedance models with representative dc side capacitive filters are employed to represent the converter interfaced wound field generation systems in an averaged-value manner. These models accurately capture the initial transient response of the generation system without incurring a significant computational penalty [24]. These systems are then connected to lumped loads via the DC buses. The resistance and inductance of the feeders connecting the generators to the DC buses has been adapted from [23] to half the length of the B787-8, that is $28.3 \mathrm{~m}$. An inductor is used as a decoupling mechanism to interconnect the DC buses (this will be varied for different simulation scenarios as will be described later). Under full-load balanced operation, solid short-circuit faults are introduced on DC Bus 2 to investigate the behavior of the DCinterconnected system under fault conditions and the impact of faultclearing time on the voltage profile of DC Bus 1. Key model parameters are summarized in Table 1.

Table 1. Parameter values of paralleled distribution network model.

\begin{tabular}{|l|l|}
\hline Rated power & $300 \mathrm{kVA}$ \\
\hline Operating voltage & $270 \mathrm{~V}$ \\
\hline Rectifier filter capacitance size & $10 \mathrm{mF}$ \\
\hline Feeder resistance & $0.801 \mathrm{~m} \Omega / \mathrm{m}$ \\
\hline Feeder inductance & $0.65 \mu \mathrm{H} / \mathrm{m}$ \\
\hline
\end{tabular}

Figure 4 illustrates the measured voltage on the healthy bus (DC Bus 1 ), with a negligible impedance inter-bus connection, when a shortcircuit fault is applied to DC Bus 2 after $5 \mathrm{~ms}$ of simulation time and then cleared after $15 \mathrm{~ms}$ of simulation time (realizing a $10 \mathrm{~ms}$ faultclearing time). The area in-between the red line depicts the compliant voltage breadth whilst in blue is the simulated voltage measured on the healthy bus. During this transient event, the voltage collapses to near-zero during the fault and then overshoots significantly once the fault has been cleared. In this manner, the voltage profile on the healthy bus does not remain within the bounds of normal transient behavior defined in MIL-STD-704F.

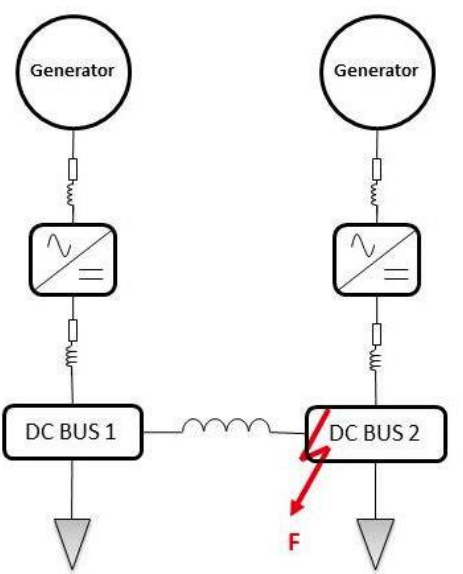

Figure 3. Single-line diagram of two-bus paralleled generation Simulink model.

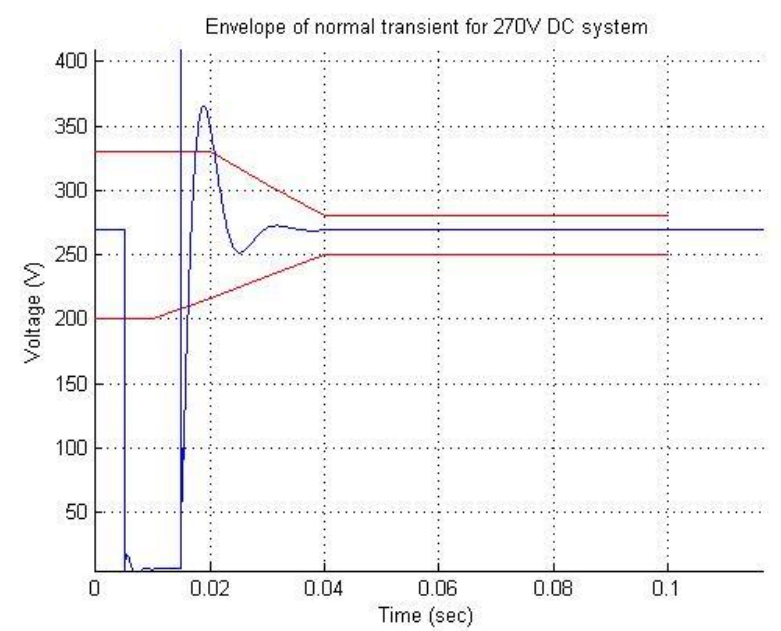

Figure 4. Voltage profile on healthy bus during fault without any passive components, for a $10 \mathrm{~ms}$ fault-clearing time.

Clearly, an effective (inductive) impedance is required for the interconnection of the two busses such that their transient responses are decoupled to some extent. This approach would provide a period of time for the fault to be cleared from the network and, if necessary, the busses isolated from each other before the voltage on the healthy system falls outside the specified limits. The authors believe there are two main variables which impact the size of inductance required to achieve voltage compliance on this bus: the type of compliance required (i.e. transient or steady state) and the time within which the bus is disconnected from the fault (either through fault clearance or bus isolation). There is an apparent trade-off between the size of inductance and these variables. The resulting mass of the 
interconnection solution will be considered as one of the key differentiators between the solutions considered.

The following simulation case studies investigate these relationships and also explore the impact of interconnecting up to four DC busses. For the next two sections the fault-clearing time is fixed at $10 \mathrm{~ms}$ to illustrate the impact of varying interconnecting inductance has on compliance to different voltage envelopes. Later sections will then vary protection operating time and inductance (whilst maintaining voltage compliance) to consider the effect this has on the weight penalty of each architecture.

\section{Simulation of two bus network}

Simulations were run where an inductive connection was employed between the DC busses. A wide range of inductance values were considered in order to observe the impact on the transient response of the healthy bus. From this analysis, suitable ratings for the interconnecting inductor which facilitate compliance with MIL-STD$704 \mathrm{~F}$ were identified for a range of simulated fault clearance times. Additionally, inductor ratings that would enable steady-state limit compliance, where the measured voltage must remain between $250 \mathrm{~V}$ and $280 \mathrm{~V}$, were also identified, in case stricter compliance is required. For illustration, the voltage profiles of the healthy bus with an $8 \mathrm{mH}$ interconnecting inductor (set to achieve compliance with normal transient limits) and with a $24 \mathrm{mH}$ inductor (set to achieve compliance with steady-state limits) are depicted in Figures 5 and 6 respectively, both with a fault-clearance time of $10 \mathrm{~ms}$. As expected, the results highlight that the tighter the required voltage envelope, the larger the size of required inductance.

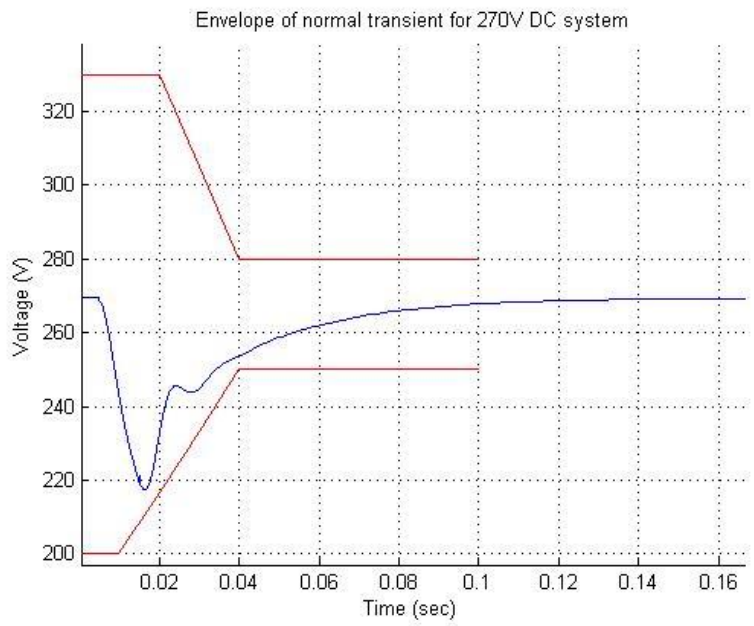

Figure 5. Voltage profile on healthy bus during fault with $8 \mathrm{mH}$ inductor, for a $10 \mathrm{~ms}$ fault-clearing time.

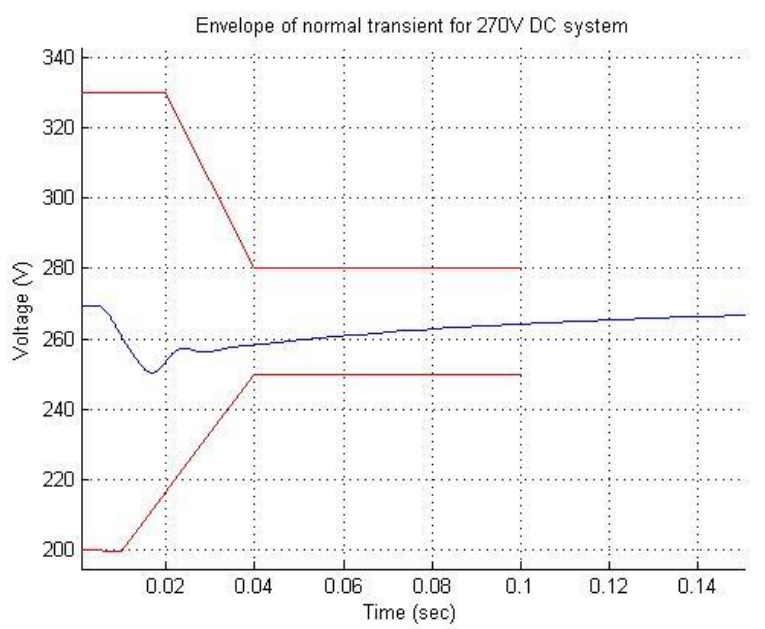

Figure 6. Voltage profile on healthy bus during fault with $24 \mathrm{mH}$ inductor, for a $10 \mathrm{~ms}$ fault-clearing time.

\section{Simulation of three and four bus network}

A similar simulation analysis was carried out for three- and four-bus architectures, shown in Figures 7 and 8 respectively. Only two different fault locations, F1 and F2, were considered due to the symmetry of the networks. For both modelled networks, each inductance in the network is rated equally.

Using the three-bus network model, the voltage profiles of the healthy bus with a $6 \mathrm{mH}$ interconnecting inductor (set to achieve compliance with normal transient limits) and a $21 \mathrm{mH}$ inductor (set to achieve compliance with steady-state limits) are depicted in Figures 9 and 10 respectively, both with a fault-clearance time of $10 \mathrm{~ms}$.

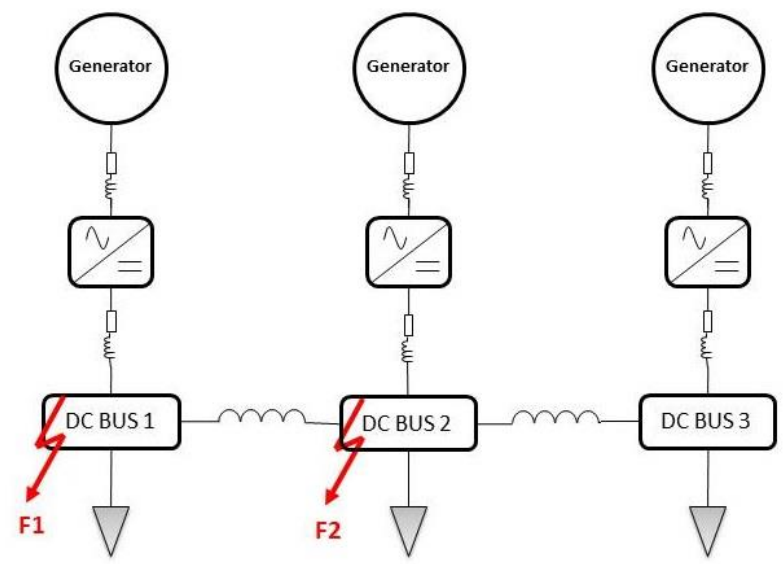

Figure 7. Single-line diagram of three-bus paralleled generation Simulink model. 


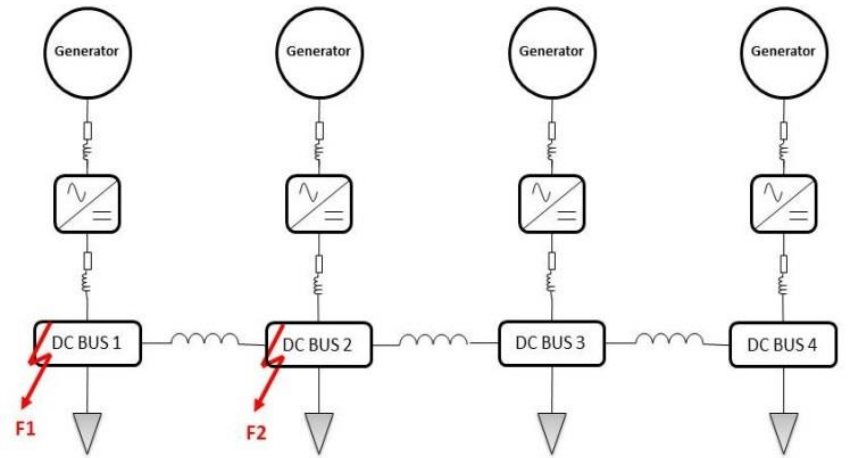

Figure 8. Single-line diagram of four-bus paralleled generation Simulink model.

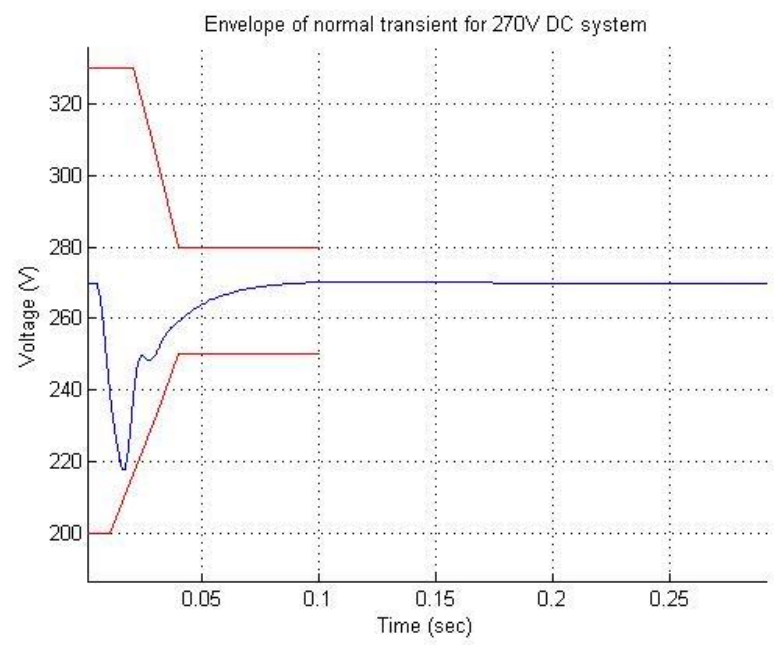

Figure 9. Voltage profile on healthy bus during fault with $6 \mathrm{mH}$ inductor, for a $10 \mathrm{~ms}$ fault-clearing time.

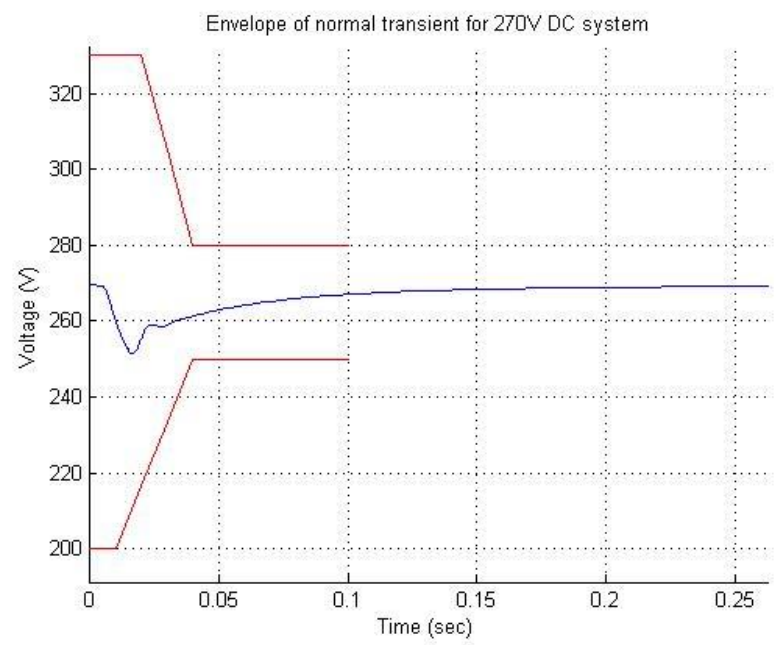

Figure 10. Voltage profile on healthy bus during fault with $21 \mathrm{mH}$ inductor, for a $10 \mathrm{~ms}$ fault-clearing time.

Using the four-bus network, the voltage profiles of the healthy bus with a $7 \mathrm{mH}$ interconnecting inductor (set to achieve compliance with normal transient limits) and a $25 \mathrm{mH}$ inductor (set to achieve compliance with steady-state limits) are depicted in Figures 11 and 12 respectively, both with a fault-clearing time of $10 \mathrm{~ms}$. For both the three and four bus architectures, larger inductances are again required to comply with the tighter voltage envelopes.

Page 5 of 8

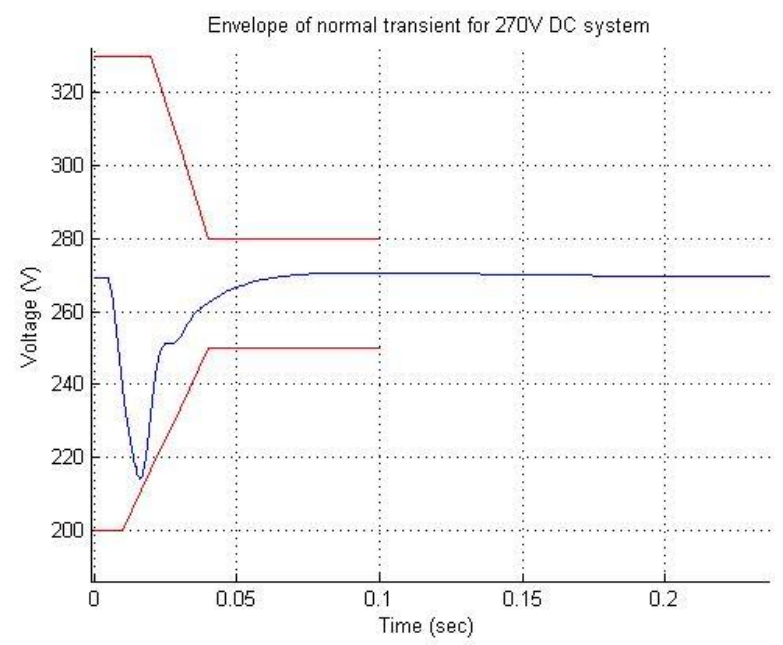

Figure 11. Voltage profile on healthy bus during fault with $7 \mathrm{mH}$ inductor, for a $10 \mathrm{~ms}$ fault-clearing time.

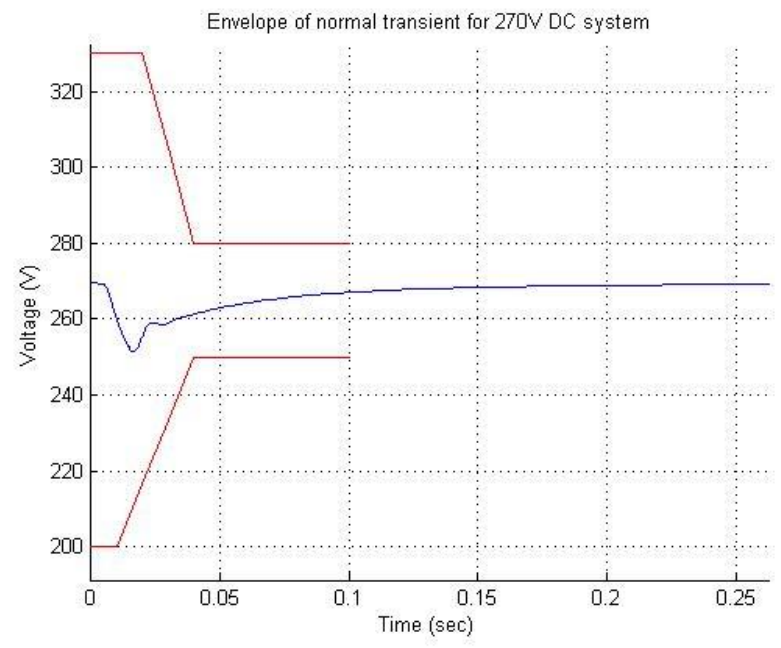

Figure 12. Voltage profile on healthy bus during fault with $25 \mathrm{mH}$ inductor, for a $10 \mathrm{~ms}$ fault-clearing time.

\section{Protection system operation}

As discussed previously, the achievable speed of operation of the protection system will impact on the size of the inductor required to achieve compliance with power quality limits during the specified fault conditions. In this manner, smaller fault-clearance times are expected to reduce the propagation of the voltage transients following the fault and hence reduce impedance required to achieve compliant interconnection.

This behaviour is illustrated in the three voltage traces extracted from the three-bus architecture model and shown in Figures 13, 14 and 15. These traces illustrate the transient behaviour of the system with fault-clearance times of $5 \mathrm{~ms}, 1 \mathrm{~ms}$ and $0.5 \mathrm{~ms}$ respectively, and using inductive interconnectors rated at $3 \mathrm{mH}, 1 \mathrm{mH}$ and $0.5 \mathrm{mH}$ respectively. It is clear from the figures that compliance can be achieved with smaller inductors if faults are cleared in a shorter time frame. 


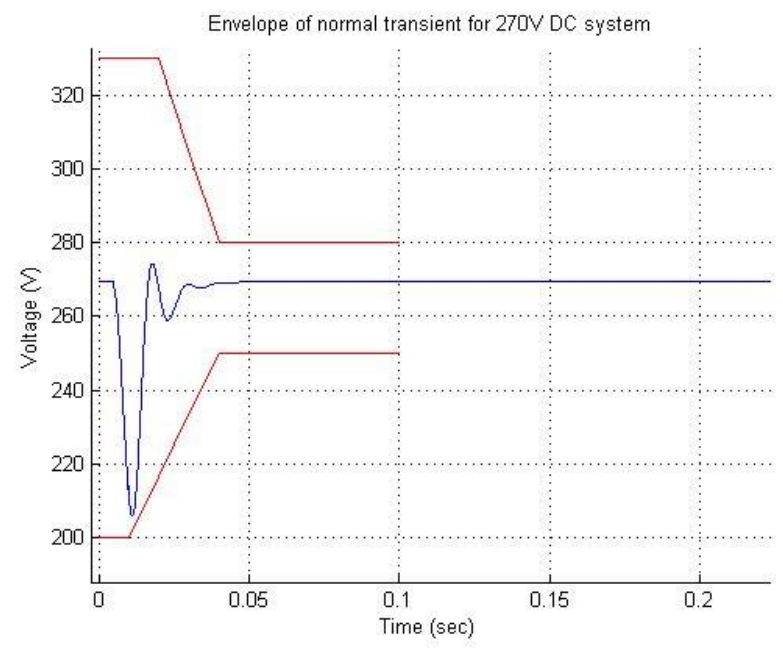

Figure 13. Voltage profile on healthy bus during fault with $3 \mathrm{mH}$ inductor, for a 5 ms fault-clearing time.

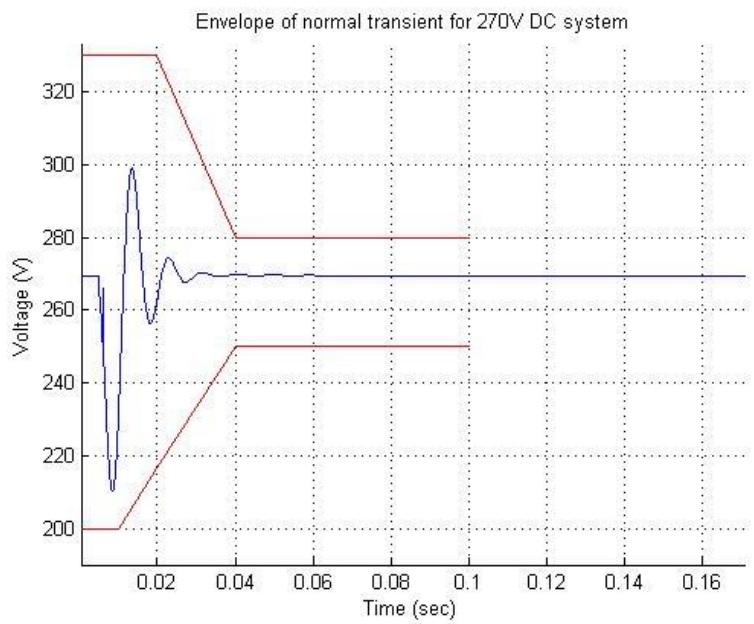

Figure 14. Voltage profile on healthy bus during fault with $1 \mathrm{mH}$ inductor, for a $1 \mathrm{~ms}$ fault-clearing time.

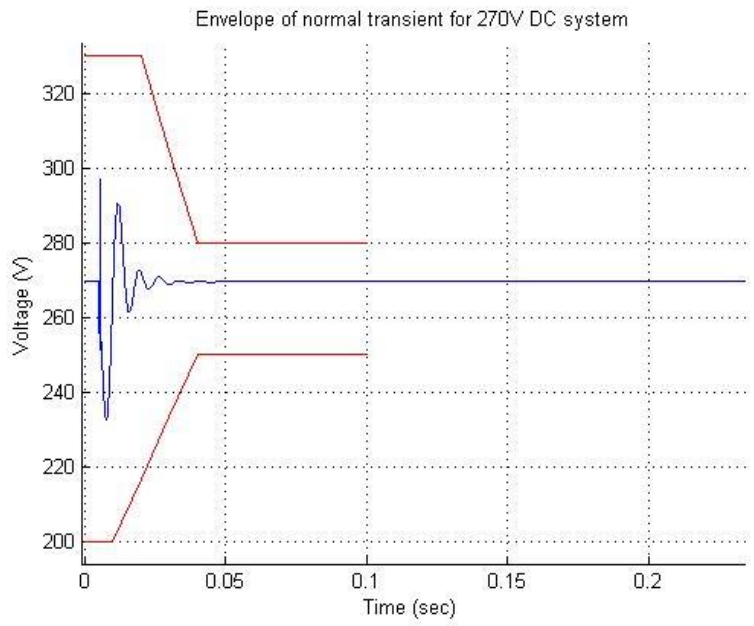

Figure 15. Voltage profile on healthy bus during fault with $0.5 \mathrm{mH}$ inductor, for a $0.5 \mathrm{~ms}$ fault-clearing time.

\section{Analysis of Solution Weights}

To quantitatively estimate the weight of the inductive interconnector required for power-quality requirements compliance, a $\mathrm{kg}$ mass per unit $\mathrm{mH}$-A rating was derived by the authors. This figure was calculated from a commercially-available aviation-grade inductor [25] to be $0.025 \mathrm{~kg} / \mathrm{mH}-\mathrm{A}$. The authors acknowledge that this number is highly approximated, nevertheless, system mass is an effective illustrator for the apparent trade between protection operating speed, compliance type and inductance sizing.

Following extensive simulations, the minimum inductance ratings required to achieve compliance with both the normal transient and steady state limits for a range of fault clearance times for two, three and four bus architectures were determined and are summarized in Tables 2-4. The respective inductor weights are calculated using the following equation:

$$
\text { Weight }=k \cdot L \cdot I_{\text {fault }_{\text {max }}}
$$

where $\mathrm{k}$ equals $0.025 \mathrm{~kg} / \mathrm{mH}-\mathrm{A}$, L represents the required impedance and $I_{\text {fault }}$ max represents the maximum fault current sensed at the interconnecting inductor. Note that all weights assume that the inductor is rated to $1 \mathrm{pu}$ continuous load current rating to accommodate the failure of a single generation unit, although the authors recognize that this rating could vary depending on the architecture design and operating logic. The weight of the bus-tie contactors is also not included in the weights specified in Tables 2-4. This is the subject of on-going work.

From tables 2 to 4 , it is evident that by increasing the number of interconnected buses there is an impact on the total weight of the architecture, as two interconnecting inductors are required for the three DC-Bus architecture and similarly three interconnecting inductors are required for the four DC-Bus architecture. Even though no general rule of thumb is applicable to all simulations results, it would appear that a 50\% reduction in fault clearing time, from $1 \mathrm{~ms}$ to $0.5 \mathrm{~ms}$, leads approximately to a $62 \%$ reduction in the total weight penalty of each architecture. Additionally, for the two DC-Bus architecture, by making the protection system 50 times faster, from 5 $\mathrm{ms}$ to $0.1 \mathrm{~ms}$ clearing time, the results suggest that that the weight penalty of the architecture is reduced by a factor of 80 , from $32 \mathrm{~kg}$ to $0.4 \mathrm{~kg}$. This would suggest that fast acting protection is critical to the potential feasibility of interconnected systems. 


\section{Summary/Conclusions}

\begin{tabular}{|c|c|c|c|c|c|c|c|c|}
\hline \multicolumn{7}{|c|}{ 2 Bus Architecture } \\
\hline Kind of compliance & \multicolumn{7}{|c|}{ Normal } & \multicolumn{5}{c|}{ Steady-state } \\
\hline $\begin{array}{c}\text { Fault-clearing time } \\
\text { (ms) }\end{array}$ & 5 & 1 & 0.5 & 0.1 & 5 & 1 & 1 & 0.1 \\
\hline $\begin{array}{c}\text { Inductor (mH) } \\
\text { Fault current (A) }\end{array}$ & 321 & 253 & 197 & 124 & 103 & 99 & 85 & 38 \\
\hline Weight (kg) & 32 & 13 & 5 & 0.4 & 36 & 15 & 7 & 0.7 \\
\hline
\end{tabular}

Table 3. Suitable inductor ratings for a three DC-bus architecture.

\begin{tabular}{|c|c|c|c|c|c|c|c|c|}
\hline \multicolumn{7}{|c|}{ 3 Bus Architecture } \\
\hline $\begin{array}{c}\text { Kind of } \\
\text { compliance }\end{array}$ & \multicolumn{3}{|c|}{ Normal } & \multicolumn{3}{c|}{ Steady-state } \\
\hline $\begin{array}{c}\text { Fault-clearing } \\
\text { time (ms) }\end{array}$ & 5 & 1 & 0.5 & 0.1 & 5 & 1 & 1 & 0.1 \\
\hline \begin{tabular}{c} 
Inductor (mH) \\
\hline $\begin{array}{c}\text { Fault current } \\
\text { (A) }\end{array}$
\end{tabular} & 3 & 1 & 0.5 & 0.1 & 13 & 5 & 2 & 1 \\
\hline $\begin{array}{c}\text { Weight (kg) } \\
\text { (m) }\end{array}$ & 62 & 22 & 8 & 1.2 & 72 & 29 & 12 & 1 \\
\hline
\end{tabular}

Table 4. Suitable inductor ratings for a four DC-bus architecture.

\begin{tabular}{|c|c|c|c|c|c|c|c|c|}
\hline \multicolumn{7}{|c|}{ 4 Bus Architecture } \\
\hline $\begin{array}{c}\text { Kind of } \\
\text { compliance }\end{array}$ & \multicolumn{3}{|c|}{ Normal } & \multicolumn{3}{c|}{ Steady-state } \\
\hline $\begin{array}{c}\text { Fault-clearing } \\
\text { time (ms) }\end{array}$ & 5 & 1 & 0.5 & 0.1 & 5 & 1 & 1 & 0.1 \\
\hline $\begin{array}{c}\text { Inductor (mH) } \\
\text { Fault current } \\
\text { (A) }\end{array}$ & 3.5 & 1 & 0.5 & 0.1 & 15 & 6 & 2.5 & 0.7 \\
\hline $\begin{array}{c}\text { Weight (kg) } \\
\text { (m) }\end{array}$ & 96 & 33 & 12 & 1.8 & 110 & 46 & 19 & 2 \\
\hline
\end{tabular}

In the quest for new, more efficient electrical architectures, interconnected generation could facilitate engine operability and fuel efficiency benefits. This paper has focused on the implementation of a 270 V DC airframe interconnection with compliance to the airworthiness standards and power-quality requirements. A paralleled distribution network software-model was created to evaluate the effectiveness of potential solution options for two, three and four DCbus architectures. Simulations showed that power-quality compliance is possible with a suitable mechanism decoupling the interconnected buses. It was also demonstrated that the speed of protection operation and the desired type of compliance are the two main influential factors that determine the size and rating of the interconnecting passive component.

Future research will focus on the detail refinement of the software model towards advanced protection strategies for a dynamicallyreconfigurable electrical network and consideration of other interconnecting technologies.

\section{References}

1. J.A. Rosero, J.A. Otrega, E. Aldabas, L. Romeral, "Moving towards a more electric aircraft", Aerospace and Electronic Systems Magazine, IEEE, vol. 22, no. 3, pp. 3-9, March 2007, doi:10.1109/MAES.2007.340500.

2. C.R. Avery, S.G. Burrow, P.H. Mellor, "Electrical generation and distribution for the more electric aircraft", presented at 42nd International Universities Power Engineering Conference 2007, pp 1007-1012, doi:10.1109/UPEC.2007.4469088.

3. The Boeing Company, "787 No Bleed Systems", AERO magazine, issue 28 , quarter 4,2007 , available online at http://www.boeing.com.

4. L. Gaines, P. Auer, G. Lane, J. Wissinger, "More electric aircraft starter-generator multi-speed transmission system", U.S. Patent US20070151258 A1 Jul. 2007.

5. J.M Kern, H.L.N. Wiegman, "Integrated electrical power extraction for aircraft engines", U.S. Patent US7468561 B2 Dec. 2008.

6. I. Moir, A. Seabridge, “Aircraft Systems: Mechanical, Electrical and Avionics Subsystem Integration”, 3rd ed., John Riley \& Sons Ltd., 2008, ISBN 978-0-470-05996-8.

7. K. Darling, "De Havilland Comet", The Crowood Press, 2005. ISBN 9781861267337.

8. Federal Aviation Administration, "Master Minimum Equipment List: B-707 and B-720", November 1990.

9. “Boeing 727 System Descriptions", http://www.boeing727.com/Data/systems/System\%20Descriptions.pdf, 22 April 2014.

10. C. Tenning, "Unplanned Characteristics of the 747-400 Electrical Power Generation System", http://www.angelfire.com/ct3/ctenning/ electrical_essays/747dash400elec/747dash400elec.html, 22 April 2014.

11. "The Boeing 737 Technical Guide", Electrical Schematics, http://www.b737.org.uk/electrics.htm\#Electrical_Schematics, May 2015.

12. The Boeing Company, "Boeing 747 Flight Crew Operations Manual (Chapter 6: Electrical)”, Smart Cockpit, April 2006, http://www.smartcockpit.com/docs/Electrical_(B747-400).pdf, 23 April 2014. 
13. G. Mackenzie-Leigh, P. Norman, S. Galloway, G. Burt, E. Orr, "Defining requirements for the implementation of interconnected generation in future civil aircraft", presented at SAE 2013 AeroTech Congress, September 2013, doi: 10.4271/2013-01-2125.

14. J. Chang, A. Wang, "New VF-power system architecture and evaluation for future aircraft", IEEE Transactions on Aerospace and Electronic Systems, vol. 42, no. 2, pp. 527-539, April 2006, doi:10.1109/TAES.2006.1642569.

15. A. Abdel-Hafez, "Power Generation and Distribution System for a More Electric Aircraft - A Review", InTech, 2012, ISBN 978953-51-0150-5.

16. M. Hirst, A. McLoughlin, P.J. Norman, S.J. Galloway, "Demonstrating the more electric engine: a step towards the power optimized aircraft", published in IET Electric Power Applications, vol. 5, no. 1, pp. 3-13, February 2011, doi: 10.1049/iet-epa.2009.0285.

17. C. Hodge, D. Mattick, "The Electric Warship II", Trans IMarE, vol. 108, part 2, pp. 109-125, 1997.

18. J. I. Hanania, "A study of some features of ac and dc electric power systems for a space station." NASA, pp. 76-84, Sept. 1983, document ID:19860004616, Accession ID: 86N14085

19. J. Haire, "F-22 Program Delivers Power System Breakthrough", U.S. Air Force News Release, July 2000.

20. S. Fletcher, "Protection of Physically Compact Multiterminal DC Power Systems", PhD thesis, University of Strathclyde, May 2013.

21. US Government, "Part 23-Airworthiness standards: Normal, utility, acrobatic, and commuter category airplanes", chapter I, Title 14 in Aeronautics and Space, US Government Publishing Office, March 2015

22. European Aviation Safety Agency, "Certification Specifications for Large Aeroplanes CS-25”, September 2007.

23. US Government, "MIL-STD-704F", September 2014.

24. S. Fletcher, P. Norman, S. Galloway, G. Burt, "Determination of protection system requirements for dc unmanned aerial vehicle electrical power networks for enhanced capability and survivability," IET Electrical Systems in Transport, vol. 1, no. 4, pp. 137-147, 2011, doi:10.1049/iet-est.2010.0070

25. Commercial product source, "Low Profile, High Current Power Inductor”, March 2015. http://www.vishay.com/ppg?34183.

\section{Contact Information}

Theodoros Kostakis

University of Strathclyde

204 George Street

Glasgow,UK

Email: theodoros.kostakis@ @strath.ac.uk

\section{Acknowledgments}

This research has been carried out as part of the Rolls-Royce UTC programme. 